\title{
A FIELD SURGICAL TEAM IN BORNEO SEPTEMBER, 1965 - MARCH, 1966
}

\author{
Major B. C. McDERMOTT, M.B.E., M.B., B.S., F.R.C.S., R.A.M.C. \\ British Military Hospital, Hong Kong.
}

\section{Introduction}

53 Field Surgical Team includes a surgeon, anaesthetist, two operating theatre technicians and a driver, and was based at Kuching General Hospital in Sarawak. The team was under the administrative command of 19 Field Ambulance, and later, 15 Field Ambulance, in support of 99 Gurkha Infantry Brigade. The primary task was to provide first line surgical support for military operations in the First Division of Sarawak, an area as large as South East England. The secondary task was to assist the local hospital to provide a surgical service for a widely spread population in country noted for its dense jungle and difficult communications. These duties were considerably assisted by our central location in Kuching. Facilities were available for a military ward of 20 beds, an average of 30 beds in the civilian wards, the use of two air-conditioned operating theatres and an out-building for stores.

\section{Surgical Procedures}

The table illustrates the variety of problems encountered. Roughly three quarters of the patients were civilians, so responsibility for all stages of treatment existed in many cases. Military cases were evacuated by air to Singapore after first line surgery.

Table

Break down of 400 Surgical Procedures

\begin{tabular}{lc||lc}
\hline \multicolumn{1}{c||}{ Nature } & $\begin{array}{c}\text { No of } \\
\text { cases }\end{array}$ & Nature & $\begin{array}{c}\text { No of } \\
\text { cases }\end{array}$ \\
\hline Neurosurgical & 10 & $\begin{array}{l}\text { Gynaecological } \\
\text { Ano-Rectal }\end{array}$ & 20 \\
Ear, Nose and Throat & 8 & 15 & 30 \\
Facio-maxillary & 7 & Burns and Plastic & 40 \\
Thyroid & 20 & Fractures & 15 \\
Thoracic & 10 & Traumatic Amputations & 35 \\
Abdominal (excluding appendix) & 80 & Gunshot wounds & 85 \\
Genito-Urinary & 25 & Miscellaneous (including appendix) & 400 \\
\hline
\end{tabular}

\section{Selected Case Reports}

\section{An Unusual example of bolus obstruction}

Dyak male aged 30 years. This previously healthy man described the onset of central abdominal colic seven days prior to admission, which became localised after two days to a continuous pain in the right iliac fossa. By the fourth day he had begun to vomit bile-stained fluid and became distended. Clinical examination was consistent with advanced appendicitis with peritonitis. After preparation with intravenous saline and gastric aspiration he was taken to theatre. At laparotomy the last 12 inches of the ileum and the caecum were inflamed and distended. The ileum contained many hard irregular 
objects. Above this level the small bowel was moderately distended but not obviously inflamed. Through an enterotomy three inches proximal to the inflamed region, 41 rambutan stones, each the size of a broad bean, were removed. The rambutan is a succulent fruit resembling a large lychee, and the patient, who was edentulous, had not attempted to extract the stones. He made an uneventful recovery and was discharged 14 days later.

Tropical Pyomyositis. Three cases of deep seated multilocular abscess involving a muscle belly were encountered. They fit the description of tropical pyomyositis given by Manson (1960).

Malay male aged 13 years. He presented with a diffuse tender swelling of the right quadriceps at mid-thigh level. The inguinal lymph nodes were enlarged and tender. After two days of bed rest and penicillin, the swelling became fluctuant centrally. A multilocular abscess containing yellow pus was drained from within the vastus lateralis muscle. Recovery was uneventful. The pre-operative white cell count showed an increase in neutrophils and eosinophils. Subsequent culture of the pus yielded Staphylococcus aureus. The eosinophilia was attributed to roundworm infestation.

Dyak female aged 10 years. This patient had a ten-day history of upper abdominal pain and swelling. There was no history of injury. Examination showed a fluctuant swelling two inches in diameter in the upper half of the right rectus abdominis. This proved on incision to be a multilocular abscess within the muscle. Culture of the pus was positive for Staphylococcus aureus. The child was of poor physique and had a pellagra-type skin rash, which responded rapidly to a vitamin-supplemented diet.

Dyak female aged 12 years. Two weeks prior to admission this girl fell on her left hip. There was a painful fluctuant swelling behind the greater trochanter on the left side. $\mathrm{X}$-ray showed a soft tissue swelling but no evidence of fracture. Inguinal lymph nodes were tender and enlarged and the white cell count was 14,000 per cu mm. A diagnosis of infected haematoma was made, but on incision and drainage the abscess cavity was found to be within the gluteus maximus. The patient's general state of nutrition was poor, and the stools contained ova and cysts of several species.

\section{Severe Head Injury}

British male aged 25 years. The patient was struck by a parachuted container of stores. He became unconscious immediately. On examination one hour later he responded to painful stimuli only, pupils were equal and pin-point, respiration was shallow and spasticity of the trunk and lower limbs was noted. The rectal temperature had risen to $104^{\circ} \mathrm{F}$. There was depression and deformity of the left fronto-temporal region of the skull and easily-demonstrated mobility of the supra-orbital ridge. X-ray confirmed a comminuted fracture of the left fronto-temporal region. After tracheostomy, a left frontal scalp flap was turned down, and detached fragments of the supra-orbital ridge were removed. Several lacerations of the underlying dura were extended to allow inspection of the severely contused frontal lobe. No obvious brain laceration or sub-dural haematoma was found, and after trimming the bone edges to leave a two inch diameter defect, the skin flap was replaced. Dura was not sutured, to allow for swelling. While in theatre the rectal temperature fell to $100^{\circ} \mathrm{F}$, but on return to the ward, which was not airconditioned, the temperature again rose to $104^{\circ} \mathrm{F}$. Surface cooling with ice water and 
fan draughts was not by itself effective, so a "lytic cocktail" of chlorpromazine, promethazine and papaverine was given intravenously in repeated doses with satisfactory control of temperature. The rectal temperature was maintained between $99^{\circ} \mathrm{F}$ and $101^{\circ} \mathrm{F}$ for five days, at which stage the patient was evacuated to Singapore. During the period in Kuching there was no improvement in consciousness, but spasticity became considerably reduced. Subsequent reports indicate that a slow recovery of consciousness occurred during the following two months.

\section{Multiple Stab Wounds}

Chinese female aged 28 years. This patient, who was twenty-five weeks pregnant, was attacked with a vegetable knife. Her condition on admission one hour later was poor. An initial examination showed 22 wounds of neck, both sides of the chest and both upper limbs. She was transfused rapidly with three pints of $O$ negative blood, which had not been cross matched, using a roller pump. At the same time a pressure dressing was applied to the sucking wound of the right thorax. A blood pressure of $100 / 70 \mathrm{~mm} \mathrm{Hg}$ was achieved after 3 pints had been transfused, and with a fourth pint running the patient was taken to theatre. Right thoracotomy revealed a penetrating wound of the upper lobe, which was closed with catgut mattress sutures. Two pints of blood were aspirated from the pleural cavity. The thoracotomy was closed with drainage to an underwater seal. The left chest contained a small quantity of air but the lung was easily inflated, so after an intercostal drain had been inserted, the stab wound in the seventh intercostal space was sutured.

Several deep wounds of the neck, which transfixed sterno-mastoid and trapezius, were drained with corrugated rubber and left unsutured. The carotid sheaths and brachial plexuses escaped injury. A total of eight pints of blood was transfused. Five days later the patient went into premature labour and a dead infant was delivered. On the ninth day the remaining soft tissue wounds were sutured and healed uneventfully: The patient was discharged on the 35 th day.

\section{Fronto-Parietal Dermoid Cyst.}

Chinese female aged 40 years. This woman complained that an abscess on the right temple had recurred several times in the preceding ten years. The condition had responded on previous occasions to simple poulticing. On examination there was a small sinus on the temple which discharged sebaceous material. Skull X-ray showed a defect one inch in diameter at the lower end of the fronto-parietal suture. A scalp flap was turned down to include the sinus, which was found to extend through the suture, and on enlarging the defect anteriorly, a dermoid cyst one and a half inches in diameter was dissected extradurally. Recovery was uneventful.

\section{Low Velocity Missile Wound}

British male aged 20 years. A .38 inch calibre pistol was discharged accidentally. The patient, standing 20 yards away, was struck in the lower abdomen. On admission thirty minutes later he was profoundly shocked. The entry wound was two inches below and to the right of the umbilicus. General abdominal rigidity and pain in the left hip were also noted. Three pints of $\mathrm{O}$ negative blood which had not been cross matched were transfused before the blood pressure could be recorded. A plain film of the abdomen showed 
the absence of psoas shadows and a bullet lodged in the left acetabulum. At laparotomy, three pints of blood were aspirated from the peritoneal cavity. Several loops of ileum were found to be perforated. The exit wound led from the peritoneal cavity through the pelvic mesocolon and there was a large left retroperitoneal haematoma. Bleeding was severe from the exit wound and was temporarily controlled with gauze packs. About eight inches of ileum were resected to include several perforations, and a further three perforations were closed with double layers of sutures. The peritoneum at the brim of the pelvis was then reflected on the left side to show complete disruption of the junction of the common iliac vein with the internal and external iliac veins. The corresponding arteries and the left ureter were intact. In view of the patient's general condition no attempt at vessel repair was made. The torn vessels were doubly ligated with linen thread. In all 12 pints of blood were given and the post-operative course was uneventful. On transfer to Singapore on the 18th day, hip movements were slightly limited and there was moderate ankle oedema on the left side.

\section{High Velocity Missile Wound}

Gurkha male aged 22 years. This soldier was shot whilst on active service with an unidentified rifle. The entry wound was in the right lower chest anteriorly; the exit was an irregular hole in the erector spinae to the right of the second lumbar vertebra. After an initial transfusion of four pints of Group $O$ blood (not cross matched) the patient was taken to the theatre. Exposure was obtained through a right thoraco-abdominal incision with division of the costal margin and the diaphragm. The missile had passed through the costo-phrenic angle, right lobe of the liver, transverse colon, second part of the duodenum and the right kidney, before making a ragged exist posteriorly. In contrast to the previous case, there was a general bursting effect in the involved viscera; this process also affected the head of the pancreas and the perinephric fascia. The liver was repaired with catgut mattress sutures after removal of several necrotic fragments. The duodenum was repaired in two layers and the kidney removed piecemeal. The damaged colon was exteriorised as a transverse colostomy and the chest was closed with drainage to an underwater seal. A further tube drain was placed to the duodenum and head of the pancreas. The initial recovery was promising. On the third day the colostomy acted well, and light diet was tolerated from the fourth day. However by the sixth day, jaundice became apparent and on the 14th day the abdominal part of the wound broke down with the liberation of pus and pieces of necrotic liver. The wound edges showed little vital reaction. A further repair with unabsorbable sutures was performed and tube drainage established to the liver. From then on the patient's general condition deteriorated, and death occurred on the 19th day. This patient sustained an overwhelming combination of visceral injuries, the most significant being the destruction of most of the right lobe of the liver. Despite the emergence of the missile, the total volume of tissue damaged was considerably greater than in the previous case. This would appear to be due to the greater energy expended by the missile in its course through the body.

\section{Military Considerations}

The terrain and the tactical situation made evacuation of the wounded difficult. It was not always possible to admit cases within six hours of injury. We were fortunate 
in having good first aid in the forward areas, determined and skilful helicopter evacuation and excellent co-operation from the staff of the local hospital. The equipment scale as an air-portable team was adequate for the majority of first line surgical procedures, but required augmentation from local sources in order to deal with civilian cases. This was due, understandably, to the wider variety of conditions encountered in the civilian wards.

\section{Conclusion}

The Borneo confrontation has been described elsewhere as a highly successful military operation. From a medical viewpoint it was a tremendous experience and a valuable lesson in the problems of a relatively undeveloped country.

An outline of the composition and surgical activities of 53 Field Surgical Team is given. Several cases are described to illustrate the scope of the work undertaken.

\section{Acknowledgements}

My thanks are due to Mr. Colin Cummings-Smith, O.B.E., F.R.C.S., and the staff of the Kuching General Hospital for their help so freely given; and to the team for their cheerful loyalty.

\section{REFERENCE}

Manson-Bahr, Sir P. (1960). 15th Ed. Mansons Tropical Diseases. p.679. Cassell, London.

\section{MEMORIALS APPEAL}

The Parachute Regiment has sought and obtained permission to establish their spiritual home in the Royal Garrison Church of All Saints, Aldershot, and therein perpetuate the memory of their fallen. Furthermore, it has been approved that those Regiments and Corps which have been associated with the Parachute Regiment in Airborne Forces and who so desire, may be commemorated in the same way.

The memorials consist of light oak panels affixed to pew ends with on them an inscription with, above, the Pegasus sign, and, beneath, the appropriate Corps badge.

The close bonds between the Parachute Regiment and the Medical Services extending as they now do for more than a quarter of a century would be most fittingly commemorated in this way. It was submitted to the Council of Colonels Commandant, Royal Army Medical Corps, that authority be given for a pew end to be contributed. The memorial to be as described in paragraph 2 and inscribed-

\section{'In Memory of All Ranks of Airborne Medical Services.'}

The Secretary of the Council of Colonels Commandant has replied to say that the Council support the idea of this form of memorial and feel that as the commemoration would be for the Airborne Medical Services over the past twenty-five years the scope of the appeal, to raise the required sum of $£ 70$, should be widened to cover retired officers and other ranks of Airborne Medical Services.

Any contributions, however small, from past and present members of Airborne Medical Services would be much appreciated. Postal orders and cheques should be made out to 'Memorials Appeals Fund' and sent to-Lt. Col. R. F. Blackburn, R.A.M.C., 23 Parachute Field Ambulance, Tournai Barracks, Aldershot, Hants. 